\title{
Modernidad y Posmodernidad en el Compositor Chilleno Contemporáneo
}

\author{
Juan Pablo González, Ph. D.
}

Para saber si un compositor es moderno o posmoderno pregúntele su opinión sobre el nuevo edificio del Congreso Nacional en Valparaíso. Los modernos lo aborrecen, lo consideran pretencioso y de mal gusto, demasiado grande y feo, les molesta su parentesco con la arquitectura egipcia, romana y fascista. Al compositor posmodemo en cambio, no le molesta, le resulta indiferente. Puede no gustarle y gustarle a la vez, sufriendo y gozando con el rompimiento que produce con su entorno urbano.

La posmodernidad nos permite ejercer la crítica de la modernidad em pleno siglo XX. Esta crítica pone en tela de juicio las certezas, dogmas y utopías que durante el presente siglo han gobernado el pensamiento político, religioso, científico y artístico occidental. A los ojos y oídos posmodernos, la modernidad aparece como la práctica de un absolutismo cultural. Ella es intolerante, maniqueísta, autoritaria, se auto-aisla y auto-censura, sólo cree en sí misma y en él progreso.

La crítica de las ideologías y verdades absolutas es un componente generativo de la posmodernidad. Para Lawson (1985: 10-11), el mundo posmoderno es un mundo sin certezas ni absolutos y fue introducido en filosofia por Nietzsche, Heidegger y Derrida con su juicio del cristianismo, la metafisicay ellogocentrismo respectivamente. El posmodernismo posee una naturaleza eclética, carece de la noción de estilo, utiliza todos los recursos a su alcance, está lleno de gente, ideas, métodos y expectativas. Como el compositor italiano Luca Lombardi (1945) mantiene, nos hemos movido de la torre de marfil del modernismo a la torre de Babel del posmodernismo (1988 173). 
Para el musicólogo francés Jean Molino hemos llegado al agotamiento de la modernidad y nuestra caída al vacio es equivalente a un nihilismo nietzschano en el arte. Posmodernidad significa para Molino el fin del terrorismo modernista: terrorismo de lo nuevo, lo puro, la forma, la función, el sistema. La búsqueda de lo nuevo, entonces, no es más un absoluto. La posmodernidad se caracteriza, continúa el autor, por el rechazo a los pares de opuestos sobre los que reposaba el modernismo que elegía siempre el "lado bueno": nuevo/antiguo, original/convencional, singular/banal, moderno/clásico, puro/impuro. Ya no existe la obligación de elegir entre estos opuestos, es el fin de los antagonismos clásicos. El posmodernismo recurre a todas las músicas, finaliza Molino, sin una voluntad totalizadora o de simple cita o collage, se desea una libre utilización de todo el material disponible. Llegamos así a una música múltiple, multivalente, heterogénea e impura (1990: 25).

Después del modernismo de los años cincuenta, que alcanzó predominio en la música chilena hasta mediados de los años ochenta, una práctica artística menos críptica y elitista que la moderna, comenzó a desarrollarse también en Chile. Ella se manifestó en el teatro (Ramón Griffero), las artes plásticas (Bororo), la arquitectura (edificio del Congreso Nacional), el video (Gloria Camiruaga), la música popular (Fulano), la literatura (Marco Antonio de la Parra) y la crítica cultural (Nelly Richards). "Ahí viene la fuerza, la voz de los ochenta", cantaba el grupo pop chilenoLos Prisioneros, al comenzar la década posmoderna en Chile.

En efecto, después de intentar el sueño revolucionario de los años sesenta y de vivir bajo un severo régimen militar, la sociedad chilena ha llegado a ser más realista, tolerante y diversificada. Recordemos que posmodernismo es también post-ideologismo; ha sido post-pinochetismo, como lo llamó Marco Antonio de la Parra, y post-progresismo en Chile. "A eseviejo no lo pescamos", decía en 1986 Javiera Parra - nieta rockera de Violeta Parra - refiriéndose a Agusto Pinochet. Revisemos cómo algunos de los rasgos posmodernos se han manifestado en la práctica musical chilena de esta última década. 


\section{Desconfiguración de los centros de poder}

El Conservatorio Nacional de Música, fundado en Santiago en 1849, ha sido desde la década de 1910 un lugar único en Chile donde estudiar composición. Su incorporación en 1929 a la Universidad de Chile, le otorgó a esta universidad el privilegio de ofrecer el grado en composición musical en Chile.

Este privilegio, que también ha constituido un monopolio, llevó a la sociedad chilena a desarrollar un particular concepto de compositor. En efecto, con frecuencia observamos cómo en Chile se considera que alguien es "compositor", sólo cuando éste ha obtenido el titulo correspondiente otorgado por nuestra sesquicentenariaUniversidad. De este modo, ser compositor en Chile equivale a ser ingeniero, médico o abogado y a tener un prestigio y reconocimiento social equivalentes.

El papel rector de la vida cultural y musical chilena, desempeñado durante gran parte de este siglo por la Universidad de Chile, se vio seriamente alterado por la política educacional del gobierno de Pinochet. Finalmente, este papel fue alterado por el aparente triunfo del mercado como rector no sólo de la vida económica sino que también cultural de los pueblos.

Los cambios ocurridos en las universidades y en la política cultural chilena a partir de 1973, produjeron que en 1981 se descontinuara la carrera de composición musical en la Universidad de Chile. ' Paralelamente, se ha incrementado la enseñanza privada de composición, las universidades Catćlicas de Santiago y Valparaíso y la Agrupación Musical Anacrusa, han iniciado cursos de composición musical y comienzan a aparecer jóvenes compositores provenientes de otras carreras musicales como pedagogía en música, licenciatura en música y tecnología del sonido. A estos jóvenes les interesa abrir espacios donde "entre toda la gente que está haciendo algo creativo" (Música joven, 1991: 35). ${ }^{2}$

Así comenzó a crecer una voz que decía "nosotros también componemos". Ya no se trataba de los cinco o siete alumnos habituales en la antigua carrera de composición, ahora eran veinte o treinta. Si a esto sumamos aquellos que desde un computador o un teclado electrónico 
descubren las maravillas que les ofrece la tecnología para crear y combinar sonidos, podemos asegurar que hoy día resulta inútil seguir pidiendo títulos universitarios para determinar si alguien es o no compositor. Para un hombre o una mujer modernos, estamos frente a un aumento del diletantismo musical, similar al producido durante el siglo XIX con la masificación del piano.

La Universidad de Chile, en un intento por retomar el liderazgo perdido, proyecta actualmente un programa de magísteren composición, donde tenga cabida una actividad composicional diversa. En dicho programa, la academia musical chilena comienza a prestar atención a una música "impura", la llamada música funcional (incidental, popular, didáctica) y al teatro musical, prácticas favoritas de la posmodernidad.

\section{Multiplicación de los márgenes}

Los márgenes de la composición musical en Chile están determinados por criterios tanto sociales como estéticos. En efecto, no sólo el no pertenecer o no haber pertenecido a la carrera de composición constituye un factor de marginalidad, sino el hecho de componer de acuerdo a una concepción circular, no linear del tiempo, también es causa de marginalidad.

La intolerancia manifiesta o latente de la vieja voz modema en Chile por la música nacionalista, minimalista, neo-romántica, utilitaria e incidental - música producto de un sentido circular del tiempo - y por el teatro musical y la ópera - música impura -, se nutre de su incondicional apego a los cánones estéticos formalistas y absolutistas centroeuropeos. Es en torno a estos cánones que se ha desarrollado el aprendizaje y práctica profesional de la composición en Chile. Esta profesionalización, como Juan Orrego-Salas mantiene (1984: 71), ha contribuido a aislar la música contemporánea del entorno social y cultural donde se practica.

Para el compositor inglés Trevor Wishart la evolución orgánica del lenguaje musical ha sido distorsionada por el academicismo de compositores que componen para ellos mismos. De acuerdo a Wishart (mi traducción), 
"el academicismo... surge cuando la evolución del lenguaje musical queda atrapado dentro de una comunidad de expertos (compositores). Estos expertos definen los criterios que ellos mismos van a satisfacer, sin ninguna referencia a otros grupos sociales, a una realidad sociomusical" (1983: 104).

Frente al purismo maniqueísta de la vanguardia moderna - que aspira a definir corrientes, estilos y escuelas con precisión - surge la contaminación del sentido y la desacralización de los signos, generada por la posmodernidad como producto de su práctica reproductiva. Compositores chilenos de entre 20 y 31 años, definen su música como un "... surtido de estilos", donde formas musicales antiguas, como la ópera barroca temprana (¿estaremos frente a un neoclasicismo retro?) coexisten con procedimientos experimentales y de la música popular (Música joven, 1991: 35). Como una forma de estar en contacto con su sociedad, estos compositores promueven la diversificación de los medios creativos. ${ }^{3}$

Esta práctica musical supone actitud creativa ecléctica, que es propia de la estética del receptor o consumidor, quien está expuesto a un producto musical diverso y heterogéneo. De esto modo, el compositor abierto al mundo sonoro de hoy, crea desde el concepto estético que posee como receptor. Llega a ser normal entonces, que un estudiante de composición estudie con distintos compositores o que practique tanto música docta como popular y jazz. Los últimos compositores chilenos de nuestro siglo poseen conciencia de formar una nueva generación creativa, autodenominada "generación del noventa". ${ }^{4}$

\section{Universalismo versus universalidad}

La fuerza cambiante de la tradición artística europea ha sido para los compositores chilenos un necesario punto de partida en su desarrollo musical. Tal tradición constituye una herencia ineludible para un compositor occidental. De este modo, los compositores chilenos se han nutrido más de una tradición artística europeo-universal que nacional o regional. Como Gerard Behague mantiene (1979: 178) el chileno desarrolló una cultura urbana con "aspiraciones internacionales" durante el siglo $\mathrm{XX}^{5}$ 
La fascinación por la cultura europea es también vista en Chile como una prolongación de una relación cultural colonialista. La Nueva Canción y luego el Nuevo Pop se han encargado de advertirle al chileno de los peligros de su obsesión por Europa. "Si la cultura es tan rica en Alemania ... por qué el próximo año no te quedas allá" le cantan Los Prisioneros al chileno eurocentrista.

La herencia artística europea es absorbida por el compositor latinoamericano desde el comienzo mismo de su educación musical y es profundizada más tarde, durante sus estudios de perfeccionamiento en el extranjero. Cual infatigables peregrinos de la música, los compositores chilenos han asistido a afamadas escuelas francesas, italianas, alemanas y norteamericanas, han participadoen prestigiosos cursos internacionales de temporada y han estudiado con maestros de renombre mundial. Entre ellos figuran Paul Dukas, Nadia Boulanger, André Jolivet y Olivier Messiaen, Paul Hindemith y Max Deutsch, Luigi Dallapiccola, Bruno Maderna y Franco Donatoni, Randall Thompson, Aaron Copland y Alberto Ginastera - el único latinoamericano de la lista.

El universalismo de los compositores de América Latina parece haber experimentado un desarrollo en tres etapas durante el siglo XX: de una etapa inicial de imitación, se progresó a una etapa intermedia de asimilación y a una etapa culminante de renovación. También podemos considerar cada una de estas etapas sincrónicamente, como actitudes simultáneas entre los músicos latinoamericanos durante la década de 1980.

En América Latina hemos sido grandes imitadores. La imitación de modas, estéticas y formas de pensamiento occidentales ha acentuado nuestra dependencia del Primer Mundo. Aprendimos a imitar entre los siglos XVII y XIX. Copiamos prácticas musicales (instrumentos, géneros, funciones, significados) renacentistas, barrocas y pré-clásicas con perfección. Luego dela independencia política deEspaña, aumentaron los modelos de imitación: óperas italianas, sinfonias alemanas, neoclasicismo a la francesa, expresionismo y dodecafonismo vienés, postserialismo darmstiano. De este modo, nuestra participación del legado musical de occidente ha sido más como "usuarios" que como "programadores". 
Sabemos que nuestros compositores latinoamericanos - a diferencia de nuestros intérpretes - sólo han tenido un lugar destacado en la historia de la música occidental con el desarrollo del llamado Nacionalismo, durante las décadas de 1920 a 1940. Basta hojear un libro de historia de la música o un catálogo discográfico para constatarlo. El resto de ellos no ha alcanzado un rol de importancia dentro de la cultura occidental. Sin embargo, los compositores latinoamericanos sí han sido importantes para nuestra burguesía local, que ha tratado de reproducir en suelo americano condiciones culturales similares a las desarrolladas por la burguesía en Europa.

Ejemplos de esta práctica musical imitativa fuera de lugar, pero, sin duda, novelesca, lo constituyen los Teatros deOpera edificadosen medio de la selva y financiados por el caucho (Manaos) y las bananas(San José de Costa Rica); las giras de compañías de opereta francesa por las salitreras del desierto de Atacama, los conservatorios instalados en el altiplano boliviano y la pampa argentina; los clavicordios llevados a lomo de mula por la sierra ecuatoriana; los violines fabricados por indígenas delParaguay; ylos hijos de esclavos negros tocandoórgano enlasiglesias de Minas Gerais.

De acuerdo a Richard Goldman, en América existió un intenso deseo de perpetuar muchas de las instituciones y prácticas de la vida artística europea, " "... sin existir las condiciones históricas y sociales que las hacían posible"'. Sintiendo que estos esfuerzos fueron principalmente de tipo competitivo, Goldman afirma queellos fueron realizados basados más en la idea de lo que era "propio" que de lo que era "necesario" (1974: 570). La idea de lo "propio" sobre lo "necesario" expresa muy bien la precupación de la burguesía del Nuevo Continente por proveerse una imagen cultivada en un sentido europeo, más que de desarrollar una cultura de acuerdo a condiciones históricas y culturales propias, como la burguesía europea lo hizo. Juan Orrego-Salas es tajante al afirmar que,

"Ninguna modificación trascendental de la música culta traída de Europa por loscolonos se hizo posibleen las Americas mientras la clase pudiente permaneció aislada del patrimonio popular, surtiéndose exclusivamente de un repertorio importado del Viejo Mundo" (1987: 174175). 
La tendenciaimitativa desarrollada por laburguesía latinoamericana a lo largo de nuestra historia - una burguesía de "segunda mano", como Eduardo Galeano nos recuerda (1971: 186) - produjo cierta voluntad universalista entrenuestros compositores. Ellos han intentado, conjusta razón, formar parte del legado artístico de occidente. Sin embargo, Europa parece no prestar demasiada atención a estos notables esfuerzos, y observa a nuestros músicos como a aquellos que quieren participar de una fiesta a la que no han sido invitados.

Luego de superada la etapa de simple imitación, algunos de nuestros compositores progresaron a una etapa intermedia de asimilación del legado musical occidental. Estos compositores participaron del movimiento universalista de música contemporánea de posguerra, movimiento moderno.

En América Latina, la práctica musical moderna resultó ser más la asimilación de técnicas seriales, aleatorias y electrónicas desarrolladas en Europa que la continuación y transformación de ellas. Fue como la obtención de un magíster en música occidental por nuestros compositores dela década de 1950. Como Orrego-Salas mantiene, el universalismo modernista frenó aún más la integración de la música contemporánea a la sociedad y cultura latinoamericana.

Existen más razones que explican el aislamiento del compositor moderno de su entorno social, que en el caso de Chile ha tenido también causas geográficas, políticas y geo-políticas. Los propios músicos chilenos reconocen este aislamiento, señalando aspectos tan diversos como la existencia de torres de marfil - donde se encierran los creadores que viven en una sociedad que no produjo la herencia artística que nutre su creación; el libre albedrío - al que nos referiremos más adelante; las distintas formas de exilio - impuesto o autoimpuesto, fuera o dentro del país; el eurocentrismo y el academicismo - al que ya nos hemos referido, y las limitaciones de una audiencia condicionada por los intereses comerciales de los Medios de Comunicación de Masas, transformados en museos de música clásica.

Superadas las etapas de imitación y asimilación, de aceptación o rechazo incondicional de postulados estéticos importados, se observa entre los compositores chilenos de fines de este siglo una relación más 
crítica con la tradición artística europea. Se trata ahora de discutir lo que dicha tradición ofrece y la manera en que ella puede ser integrada a una práctica musical desarrollada en este continente. Una práctica que considere también el mundo sonoro de América Latina, formado por "insólitos factores de crecimiento, pulsiones anímicas, estratos raciales, injertos y transplantes", como dice Alejo Carpentier (1987).

Después de haber sido imitada y asimilada, la tradición artística europea puede ser renovada en América Latina. Esta renovación, que nos conduciría a una necesaria independencia cultural respecto a Europa, podrá llevar al compositor latinoamericano a dejar de ser universalista y comenzar a ser universal. Curiosamente, esta universalidad parece ser lograda una vez que se asume plenamente la particularidad del mundo sonoro y cultural en el que se habita, lo que le permite al compositor formar parte de esa aldea global que también existeen la creación musical contemporánea.

\section{Raíces y libre albedrío}

En Chile, compositores conservadores y vanguardistas, músicos de rock y de jazz se han visto a sí mismos como artistas occidentales viviendo en una tierra sin tradiciones musicales. En efecto, la ausencia de una tradición musical docta, jazzística o rockera en América Latina hace que muchos de nuestros músicos se sientan sin un vínculo hacia el pasado musical local, comportándose como inmigrantes en su propia tierra. Alejandro Guarello (1951) señala,

"... estamos echando nuestras raíces porque la cultura latinoamericana se está gestando hoy". ("Alejandro Guarello ...", 1989: 5)

Estos músicos no reconocen raíces en Latinoamérica, sólo asimilan, en una suerte de antropofagia, su práctica musical actual, que podrá constituirse en las raíces del futuro. De hecho, Los Prisioneros no sólo tuvieron a The Beatles, The Clash o a Sex Pistols como modelo, también tuvieron a Los Angeles Negros y a Lucho Gatica. ¿Formarán Los Jaivas 
y Congreso las raíces de Huara, el Quilapayún las raices de Napalé, la Fresia Soto las raíces de Miriam Hernándezy Los Trapos las de La Ley?

Andrés Alcalde (1952), luego de formarse como compositor en Chile con Alfonso Letelier, Juan Lèmann y Cirilo Vila durante la década de 1970, viajó a Roma en 1983 a estudiar con Franco Donatoni. Desde su regreso en 1984, Alcalde ha desarrollado una constante labor de enseñanza de composición en Santiago y Valparaíso. Su aprendizaje con Donatoni influyó poderosamente en su concepción musical actualy, a su vez, en los muchos alumnos de composición que ha tenido. Podemos hablar de una escuela "donatoniana" desarrollada en Chile por Alcalde y sus discípulos

Esta práctica composicional hace surgir la música de la escritura, mediante la llamada "manipulación de signos gráficos", concepto de tintes posmodernos. El material sonoro es organizado mediante una suerte de auto-desencadenamiento que también produce el agotamiento de la obra. Junto con definir una figura sonora inicial, se definen los parámetros que la modificarán. Lo temático en una obra donatoniana reside tanto en la figura como en los mecanismos que la transforman.

La música de Alcalde tiene la virtud de mantener una plasticidad, soltura y gracia por sobre la mecanicidad y obviedad que puede suponer el uso sistemático del principio de auto-desencadenamiento. Esta plasticidad, se aprecia tanto en las figuras compuestas por Alcalde como en los mecanismos de transformación ideados por el compositor.

En "Sempre", el solo inicial del piccolo, con su incesante ritmo y belleza lógica, parece una danza de sicus, o el canto de un pájaro encantado. ${ }^{6}$ En "Off the tap" (1984) para clarinete solo, Alcalde incrementa la plasticidad de la primera figura, manifestada en sus rápidos cambios de dirección, con la expansión de sus saltos ormamentales.

Entre los jóvenes compositores que han estudiado con Alcalde encontramos similares recursos "donatonianos", aunque manejados con distintos resultados. En "786/Per", de José Miguel Miranda, el piano está usado casi en forma monódica, importando más la línea que la textura. La obra se estructura claramente en torno a procedimientos de auto-desencadenamiento y agotamiento de los recursos de 
manipulación. Lo mismo sucede en “... e forpio” (1987), de Sergio Cornejo (1953). donde el juego de la manipulación se hace más evidente y en "Dou" (1989), de Boris Alvarado (1962), compositor de Valparaíso que impregna su dúo para cello y piano del sonido vital y dramático de una orquesta de tangos porteña. En "Son" (1986) para guitarra, de José Miguel Tobar, una figura de ritmo incesantey vital experimenta procesos graduales de crecimiento y extinción. Apreciamos una vez más esa concepción lógica, lúdica y auto-referente de la manipulación de signos. ${ }^{7}$

En "Acse", trío para flauta, clarinete y violin de Pablo Aranda (1960), el meticuloso ejercicio donatiano sirve de base para desarrollar la pasión por el sonido. Esta pasión se manifiesta en la detallada precupación del compositor por los transientes de la vibración sonora (ataque, mantención, resonancia, dinámica) y por el aislamiento puntillista de los sonidos.

En una suerte de "sensualidad sonora", Aranda produce una obra donde la continuidad se hace evidente en el uso consecutivo de modelos de autodesencadenamiento que marcan las secciones temáticas de la composición. Estos modelos, junto a la manipulación del sonido, establecen también los contrastes de la obra en una suerte de arrebatos dinámicos, de articulación y timbrísticos.

Los músicos chilenos vienen proclamando desde la década de 1980, la apertura y asimilación crítica de un amplio número deinfluencias intelectuales y estéticas. Sintetizando o superponiendo una suma de influencias sociales y culturales, tanto seleccionadas como impuestas, y desarrollando una interpretación personal de ellas, músicos latinoamericanos construyen la tradición que les falta.

El compositor irlandés Frank Corcoran nos recuerda que los compositores sinunatradición musical propia tienenla ventaja deacercarse a la música con ojos y oídos fríos. Para Corcoran, estos compositores pueden ser ecléticos en el mejor sentido del término, (mi traducción)

“... eligiendo para sus necesidades expresivas del vasto vertedero de posibilidades sintácticas que los años de post-guerra han lanzado" . $(1983: 44)$ 
El compositor chileno Carlos Riesco tuvo la magnifica ocurrencia de perguntarle a Olivier Messiaen por el sentido de ser compositor chileno. El venerable compositor francés respondió,

"Tal vez signifique actuar libremente. Nosotros soportamos el peso de una tradición muchas veces centenaria, que nos obliga de múltiples maneras. Ustedes en cambio, están en la envidiable posición de poder actuar con libertad, sin tener que ser originales por sobre todo, sin tener que ir en contra de nada o en contra de nadia, sin tener que combatir con la sombra de Debussy"'. (Riesco, 1988: 275)

Este libre albedrío composicional ha sido proclamado y practicado por músicos chilenos de todas generaciones y estilos. Ellos sienten la libertad del que no se debe a ninguna tradición local. Dice Alejandro Guarello:

"Somos como una fragua o, si se prefiere, como un tarro basurero. Aquí ha caído de todo. Chile es un país particularmente cosmopolita en el que no hay tradición indígena: los españoles arrasaron con todo. Lo que ahora hay es una mezcla de influencias, por eso el asunto de las raices y el folklore es un mito". ("Alejandro Guarello...", 1989:5)

En "Incontri(o)" (1984) para flauta, clarinete y cello, Guarello demuenstra una musicalidad clásica mediante el uso depurado de los recursos instrumentales y la clara puntación de la forma. Es una música cuyos mecanismos de continuidad son menos evidentes, el contraste alcanza límites extremos en ella, una música que no se da tregua, profundamente seria, árida y a veces ácidamente irónica - como la de un Mahler o un Berg borracho. ${ }^{8}$

Luego de pasada la fiebre modernista de la década de 1950, los músicos chilenos vuelven a interesarse en el desarrollo de una música occidental con raices en tradiciones vernáculos latinoamericanas. Prolongando a nuestro suelo las vertientes nacionalistas del romanticismo y del neo-clasicismo europeos, se desarrolló en Chile desde finales del siglo XIX una música docta con raíces. Esto se logró mediante la cita, estilización o elaboración de procedimientos rítmicos, melódicos, armónicos o timbrísticos de la música vernácula; la referencia al paisaje 
y a las tradiciones folklóricas nacionales; el uso de procedimientos melódicos derivados de los modos criollos e indígenas de hablar; el uso de elementos literarios chilenos; y la presencia de una sobriedad y melancolía características del modo de ser (montañés) del chileno.

Sin embargo, para los compositores chilenos contemporáneos, una música nacional puede ser también desarrollada como consecuencia de ciertos enfoques composicionales y de actitudes hacia la práctica musical, y por la presencia no de la música vernácula en sí, sino de principios de la música vernácula. Para estos músicos, una música nacional es aquella que expresa, refleje, influye y tiene una función y un propósito dentro de una sociedad determinada. ${ }^{9}$

El rescate, desarrollo y síntesis de tradiciones musicales latinoamericanas es visto por los músicos chilenos como un medio para lograr independencia política, cultural y artística, además de identidad y libertad en América Latina. Como el etnomusicólogo ganés Kwabena Nketia mantiene, la tradición en los países del TercerMundo es respetada y valorada como un factor necesario de estabilización, y como un fondo de buenos recursos que pueden proveer un marco a los modos de expresión del músico creativo (1982: 83).

A diferencia del auto-aislamiento social practicado y proclamado por el compositor moderno, en la posmodernidad importa la inserción del creador en el cuerpo social. José Miguel Miranda señala,

"Me parece que hay que estar en contacto... Hay que tomar conciencia de la carga histórica que tiene la música". (en Muñoz, 1992: 14)

Desde 1984, Gabriel Matthey (1955) se ha interesado en la cultura y música mapuche como marco de referencia para su actividad creativa. El compositor se siente atraído por el mundo sonoro mapuche - el sonido del mapudungun, por ejemplo - y por la cosmovisión mapuche. Desea transmitir en su obra la experiencia de temporalidad cíclica y eterna que se vive en el ritual indigena y el dualismo de la cultura mapuche.

Eduardo Cáceres quiso rescatar la expresión interior del canto de la machi en "Epigramas" (1991) para contralto, clarinete, violín, cello y piano, sobre textos del poeta mapuche Elicura Chihuailaf. En el primer 
epigrama musicalizado, "Iniciación" (2'10"), predomina la sonoridad de segunda, intervalo usado en forma cerrada como cluster o abierta como séptima o novena, y como duplicación melódica. Los rasgos mapuches de la pieza se hacen evidentes en su melodía, cantada en mapudungun y formada por pies rítmicos troqueos, notas repetidas, glissandos ascendentes hacia notas indefinidas y giros de tercera.

A Cáceres le atrae el fondo mágico, religioso y primigenio de la música y la cultura indígena. Siente una fuerte vinculación entre el lenguaje de la música contemporánea y la práctica musical indígena. Frente al agotamiento en lo formal del caminho occidental, señala Cáceres, las tradiciones musicales no occidentales ofrecen un sentido, un contenido que le interesa rescatar.

Un impulso similar se observa en obras de Patricio Wang (1952) y Leonardo García (1967). En "Alter Ego" (1983) para dos trompetas, Wang utiliza un instrumento que posee cierta carga semántica para el chileno por su amplio uso entre los mapuches (trutruka, nolquin, pututu) y su presencia en bandas militares (españolas y chilenas), circenses y andinas. Esta música, de contrapunto stravinsquiano y modal, es una música "impura", su expresividad está nutridadeimágenesy asociaciones con otras músicas.

En "Ceremonial", para flauta en sol, piccolo y zampoñas, de Leonardo García, estamos frente a una música que recoge el sonido vernáculo de América y lo sitúa en el marco contemporáneo de la exploración del color, la articulación y la microtonalidad. Es el viento de Los Andes que se abre paso a través de rutas sonoras que no le son del todo ajenas, pues el sonido ancestral se confunde en América con el sonido del presente.

Podemos afirmar, a modo de conclusión, que la música chilena de fin de siglo posee rasgos tanto modernos como posmodernos. Entre estos últimos se destacan la práctica de un universalismo crítico y con raíces, de un nacionalismo "post-colonial" no dogmático y de un eclecticismo tanto espontáneo como intencional. 


\section{NOTAS}

1. Roberto Escobar (1970: 157-166) entrega una visión socio-histórica de la enseñanza de composición en Chile hasta fines de la década de 1960. Alejandro Guarello comenta la situación de mediados de la década de 1980 en Naranjo, 1987: 56.

2. Ver por ejemplo, Iván Barrientos, Suite Aysén Santiago: Columbia KNIA 1582,1990 (casete).

3. Ver entrevista a Miguel Miranda en Muñoz, 1992: 14.

4. Ver por ejemplo, "Indómito" para fagot solo de Carlos Silva (1965), editado en el casete doble T3 ${ }^{c e r}$ Encuentro de Música Contemporánea Compositores Chilenos. Santiago: Agrupación Música Anacrusa, 1989.

5. El término "estreno mundial", com el que se anuncia en Santiago el estreno de una obra chilena, ha sido parodiado por la generación de compositores de 1990 como "estreno intergaláctico".

6. "Sempre", para piccolo, violín, cello, piano y clarinete, fue editado en el casete doble $2^{\circ}$ Encuentro de Música Contemporánea Compositores Chilenos. Santiago: EMI, 1988.

7. "786/Per" y "Son" fueron editados en el casete doble $2^{\circ}$ Encuentro de Música Contemporánea Compositores Chilenos. Santiago: EMI, 1988. " “.. e forpio" y "Dou" fueron editados en el casete doble T3 ${ }^{\text {cer Encuentro de }}$ Música Contemporánea Compositores Chilenos. Santiago: Agrupación Música Anacrusa, 1989.

8. "Incontri(0)" fue editado en el casete doble T3cer Encuentro de Música Contemporánea Compositores Chilenos. Santiago: Agrupación Música Anacrusa, 1989.

9. Los músicos ligados a la Nueva Canción Chilena en el exilio - como Sergio Ortega, Eduardo Carrasco y Horacio Salinas - desarrollaron un universalismo con raices al situar las tradiciones musicales de su "patria grande" América Latina - en el marco de otras tradiciones del mundo; al inventar de nuevo lo que ya había sido inventado en Europa, pero adaptando las ideas originales a la realidad latinoamericana; y componiendo y tocando para un público tanto europeo como latinoamericano.

\section{BIBLIOGRAFIA}

"Alejandro Guarello: un juicio sin atenuantes". Adagio, 1(2):4-5, mayo 1989. BÉHAGUE, Gerard. Music in Latin America: an Introduction. Englewood Clifs, New Jersey: Prentice-Hall, 1979. 
CARPENTIER, Alejo. "América Latina en la confluencia de las coordenadas históricas y su repercusión en la música" in América Latina en su Música. Isabel Aretz ed. México: Siglo veintiuno editores, 1987, pp. 7-19.

CORCORAN, Frank. "New Irish music". Interface, 12(1-2):41-44, enero 1983. ESCOBAR, Roberto. Músicos sin pasado. Santiago: Editorial Pomaire, 1970.

GALEANO, Eduardo. Las Venas Abiertas de América Latina. México: Siglo veintiuno editores, 1971.

GOLDMAN, Richard Franko. "Music in the United States" in New Oxford History of Music, vol. X. Ed. J.A. Westrup et al. London: Osford University Press, 1974. pp. 569-634.

LAWSON, Hilary. Reflexivity. The post-modern predicament.London: Hutchinson, 1985.

LOMBARDI, Luca. "From the Ivory Tower to the Tower of Babel". Interface, 17:173-176, 1988.

MOLINO, Jean. "Du plaisir au jugement: les problèmes de l'évaluation". Analyse Musicale, 19: 16-26, avril 1990.

MUÑOZ, Juan Antonio. "Música para el Teatro, Música con Efecto Lubricador". El Mercurio. Santiago, 12 junio 1992, pp. W14-15.

“Música joven, música de hoy". La Epoca. Santiago, 10 noviembre 1992, p. 35.

NARANJO, René. "Compositores chilenos. La queja de los pentagramas". Apsi 12(212):55-56, 10-16 agosto 1987.

NKETIA, Kwabena J.H. "Developing Contemporary Idioms out of Traditional Music". Studia Musicologica, 24:81-97, Supplementum, 1982.

ORREGO-SALAS, Juan. "La música latinoamericana: tránsito del archivo a la sala de conciertos". Revista Musical Chilena, 38(161)70-76, enero-junio 1984.

"Técnica y estética". América Latina en su Música. Isabel Aretz ed. México: Siglo veintiuno editores, 1987, pp. 174-198.

RIESCO, Carlos. "Evocación de Carlos Isamitt y consideraciones sobre la creación artística". Boletin Academia Chilena de Bellas Artes, 1: 263-277, 1988.

WISHART, Trevor. "Music/Change", Interface, 12(1-2):103-109, enero 1983. 